\title{
Crystal morphology control of synthetic giniite for enhanced photo-Fenton photocatalytic activity against the emerging pollutant metronidazole
}

\author{
P. M. Martins ${ }^{1,2,3^{*}}$, H. Salazar ${ }^{1,2,3^{*}}$, L. Aoudjit ${ }^{4}$, R. Gonçalves ${ }^{2}$, D. Zioui ${ }^{4}$, A. Fidalgo-Marijuan ${ }^{5}$, \\ C. M. Costa ${ }^{1,2}$, S. Ferdov ${ }^{1}$ and S. Lanceros-Mendez ${ }^{5,6^{*}}$ \\ ${ }^{1}$ Centre/Department of Physics, ${ }^{2}$ Centre/Department of Chemistry, University of Minho, Campus de Gualtar, 4710-057 \\ Braga, Portugal \\ ${ }^{3} I B-S$ - Institute for Research and Innovation on Bio-Sustainability, University of \\ Minho, 4710-057, Braga, Portugal \\ ${ }^{4}$ Unité de Développement des équipements Solaires, UDES /Centre de Développement des Energies Renouvelables, CDER, \\ Bou Ismail, 42415, W. Tipaza, Algérie \\ ${ }^{5}$ BCMaterials, Basque Center for Materials, Applications and Nanostructures, UPV/EHU Science Park, 48940 Leioa, Spain \\ ${ }^{6}$ IKERBASQUE, Basque Foundation for Science, 48013 Bilbao, Spain \\ * These authors equally contributed for this work
}

\begin{abstract}
Metronidazole (MNZ) is a recalcitrant antibiotic with toxic and carcinogenic effects in aquatic environments. In this work, $\mathrm{Fe}_{5}\left(\mathrm{PO}_{4}\right)_{4}(\mathrm{OH})_{3} \cdot 2 \mathrm{H}_{2} \mathrm{O}$ (giniite) particles were synthesised with three different alkaline cations $\left(\mathrm{Li}^{+}, \mathrm{Na}^{+}\right.$and $\left.\mathrm{K}^{+}\right)$and used as Fenton catalysts for MNZ removal. It is shown that the addition of different cations during the hydrothermal synthesis process promote different morphologies from asterisk-like to flower-like and branches-like, maintaining the crystalline structure of pure giniite. The photocatalytic activity of these particles was then evaluated through the degradation of MNZ under sunlight radiation for 9 hours. The results indicate that the alkaline cation has a predominant role in the photocatalytic efficiency, as demonstrated by the superior degradation efficiencies of $\mathrm{Na} @$ giniite particles (91.2\% and $72.5 \%$ with giniite concentration of $0.2 \mathrm{~g} / \mathrm{L}$ and $0.07 \mathrm{~g} / \mathrm{L}$, respectively), related with its high surface area $\left(10.7 \mathrm{~m}^{2} / \mathrm{g}\right)$. Thus, it is demonstrated the suitability of $\mathrm{Na} @$ giniite particles as Fenton catalyst for MNZ removal from water.
\end{abstract}

Keywords: advanced oxidation process, emergent pollutants, giniite, metronidazole, sunlight irradiation 


\section{Introduction}

Water pollution has become a severe environmental problem all over the world, and the treatment of organically contaminated wastewater is a growing concern [1]. Among all, antibiotics have been frequently found in both aquatic and terrestrial environments. The excessive consumption of these compounds leads to their presence in water, inducing proliferation of bacterial drug resistance and increasing the concern about their toxicity and poor metabolisation [2]. Metronidazole (MNZ) is a widely used antibiotic in the treatment of several infections caused by anaerobic bacteria, bacteroides and protozoa [3], it is also used as an additive in fish and poultry feed to eliminate parasites [4]. As a consequence, MNZ is accumulated in animals and effluents from hospitals and industries [5, 6]. It is considered toxic to aquatic environments, genotoxic to humans, carcinogenic and mutagenic [7]. Due to its low degradability and high solubility in water, the efficient removal of MNZ from wastewater is an urgent need.

Advanced oxidation processes (AOPs) are photochemical technologies used for the degradation of resistant organic compounds like pharmaceuticals [8], pesticides [9] or phenolic compounds [10]. AOPs are based on oxidation reactions and consequent formation of hydroxyl radicals, which can break links in resistant and stable organic compounds. In the Fenton process, hydroxyl radicals are formed through the reaction of $\mathrm{H}_{2} \mathrm{O}_{2}$ with $\mathrm{Fe}^{2+}$ ions under strongly acidic conditions. It consists of the oxidation of $\mathrm{Fe}^{2+}$ to $\mathrm{Fe}^{3+}$ along with the reduction of $\mathrm{H}_{2} \mathrm{O}_{2}$, to produce ${ }^{\circ} \mathrm{OH}$ radicals. Compared with other A.O.P.s, Fenton process is widely applied due to its simple operation, broad application range, fast degradation and mineralisation of compounds and strong anti-interference ability [11]. However, the application of Fenton process is limited by a sharp working $\mathrm{pH}$ range $(2.5-3.5)$, the requirements for further separation and the significant amount of ferric hydroxide formed during the process [12]. To overcome these limitations, some Fenton catalysts, such as iron oxides [13], carbon-based composites [14] and iron phosphates [12], have been successfully prepared.

Iron phosphates are materials with exciting properties, such as the oxidative dehydrogenation catalysis and the crystal chemistry [15]. In particular, giniite, $\mathrm{Fe}_{5}$ $\left(\mathrm{PO}_{4}\right)_{4}(\mathrm{OH})_{3} \cdot 2 \mathrm{H}_{2} \mathrm{O}$, is used for photocatalytic degradation of organic dyes [16-18] and in lithium-ion battery applications [19]. Recently, Duan et al. [16] prepared giniite microcrystals and evaluated their photocatalytic activity, showing that their performance is highly dependent on the exposed faces. Different methods are used for the synthesis of synthetic giniite, such as sol-gel, solid-state reaction, electrochemical synthesis, or hydrothermal, among others [20-22]. 
Giniite obtained by hydrothermal synthesis process, using different inorganic and organic precursors and various parameters, as temperature, $\mathrm{pH}$, stoichiometric ratios and time of synthesis, was prepared to obtain a wide variety of morphologies [19, 23].

In this work, the influence of alkaline cations $\left(\mathrm{Li}^{+}, \mathrm{Na}^{+}, \mathrm{K}^{+}\right)$during the synthesis of giniite on crystal morphology was investigated. Three different morphologies were obtained, and their photocatalytic activity was evaluated through the degradation of MNZ under sunlight radiation.

\section{MATERIALS AND METHODS}

\subsection{Reagents}

Metronidazole ( $\mathrm{M}=171.16 \mathrm{~g} / \mathrm{mol}$ ), with the chemical formula $\mathrm{C}_{6} \mathrm{H}_{9} \mathrm{~N}_{3} \mathrm{O}_{3}$ and a maximum absorption at a wavelength of $284 \mathrm{~nm}$, was purchased from Merck. Hydrogen peroxide $\left(\mathrm{H}_{2} \mathrm{O}_{2}\right.$, $30 \% \mathrm{w} / \mathrm{w})$, sodium hydroxide $(\mathrm{NaOH}, 97 \%)$ and sulfuric acid $\left(\mathrm{H}_{2} \mathrm{SO}_{4}, 95 \%\right)$ were purchased from HACH Company. All solutions were prepared with ultrapure water (Milli-Q). Phosphoric acid $\left(85 \%, \mathrm{H}_{3} \mathrm{PO}_{4}\right)$, lithium hydroxide $(97 \%, \mathrm{LIOH})$ and potassium hydroxide $(97 \%, \mathrm{KOH})$ were purchased from Merck. Iron nitrate $\left(99 \%, \mathrm{FeNO}_{3}\right)$ was purchased from Panreac.

\subsection{Synthesis of giniite}

The synthesis of giniite was performed according to previous studies [19]. The first step was the preparation of three separated solutions: (1) dissolution of $0.29 \mathrm{~g}$ of $\mathrm{H}_{3} \mathrm{PO}_{4}$ in $5 \mathrm{~g}$ of $\mathrm{UP}$ water; (2) dissolution of $0.85 \mathrm{~g}$ of $\mathrm{FeNO}_{3}$ in $10 \mathrm{~g}$ of UP water; (3) dissolution of $0.44 \mathrm{~g}$ of $\mathrm{LiOH}$, $\mathrm{NaOH}$ or $\mathrm{KOH}$ in UP water, with $\mathrm{pH}$ adjustment to 4 . The second step was the mixing of the three solutions, following the order $1+2+3$. The mixture was then magnetically stirred for 5 minutes to achieve homogeneity and, after that, placed into a Teflon-lined stainless-steel autoclave to heat at $230^{\circ} \mathrm{C}$ for 72 hours. Finally, the powders were filtered, washed with water and dried overnight at $60^{\circ} \mathrm{C}$.

\subsection{Characterisation of giniite}

The crystal morphological characterisation was assessed by scanning electron microscopy (SEM) with an FEI. Nova 200 (FEG/SEM). The crystal structure and phase composition of the three giniite samples were evaluated through X-ray diffraction (XRD), using a Bruker D8 Discover diffractometer. The XRD parameters were: $\theta-2 \theta$ scan mode; a range of $0-60^{\circ}$ with a scan step of $0.06 \%$ s. The chemical structure of the prepared giniite was evaluated by Fourier Transformed Infrared Spectroscopy (FTIR), with a Jasco FT/IR-4100 system, carried out from 
4000 to $600 \mathrm{~cm}^{-1}$ with a resolution of $4 \mathrm{~cm}^{-1}$ and 64 scans in the attenuated total reflectance (ATR) mode.

Samples porosity and surface area were determined by mercury intrusion porosimetry (MIP) in a Quantachrome Instruments Poremaster-60 GT operating in the pressure range from vacuum $\left(10^{-4} \mathrm{MPa}\right)$ to $414 \mathrm{MPa}$. Samples were degassed in situ at $110{ }^{\circ} \mathrm{C}$ during $12 \mathrm{~h}$ before measurement. A contact angle of $140^{\circ}$ and a surface tension of $480 \mathrm{dyn} / \mathrm{cm}$ for mercury and a pressure equilibration time of $11 \mathrm{~s}$ were used. Before the measurement of MIP the He density for all the samples were measured in a Quantachrome Instruments automatic Micro Ultrapycnometer.

\subsection{Photocatalytic assays}

The Fenton photocatalytic activity of giniite was evaluated through the direct contact between giniite particles and a $10 \mathrm{mg} / \mathrm{L} \mathrm{MNZ} \mathrm{solution.} \mathrm{The} \mathrm{used} \mathrm{experimental} \mathrm{setup} \mathrm{is} \mathrm{shown}$ in ¿Error! No se encuentra el origen de la referencia.Figure 1.

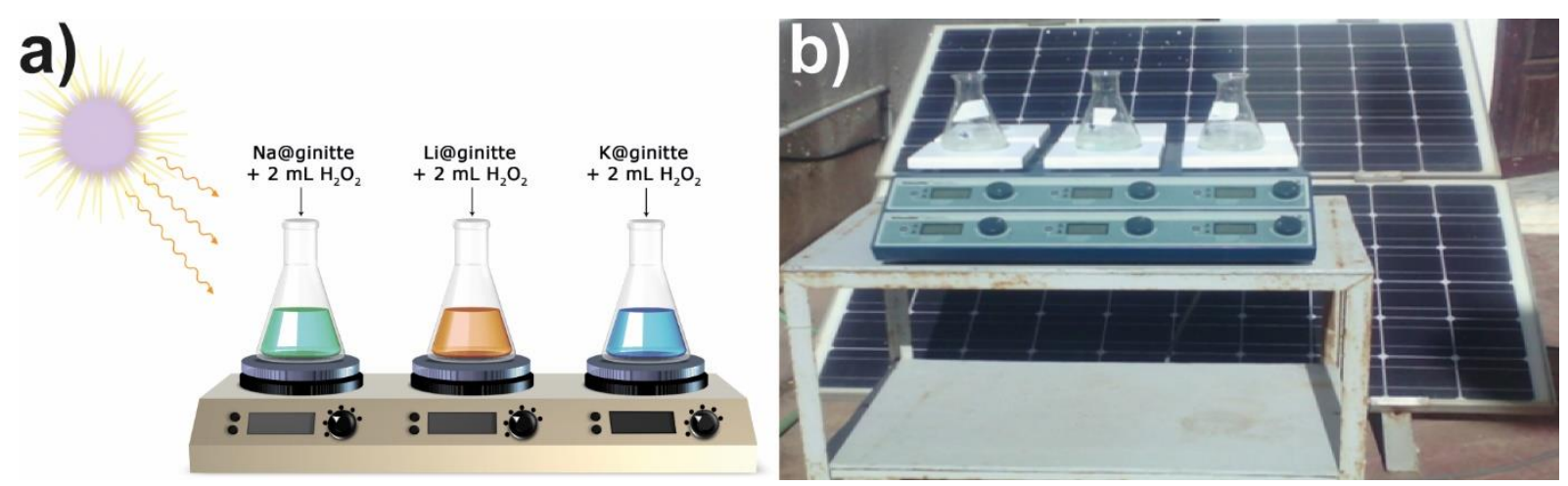

Figure 1. (a)_The s_Schematic representation of the experimental setup used for the photo Fenton photocatalytic assays; (b) picture of the real setup.

Photocatalytic experiments were performed in a beaker with $150 \mathrm{~mL}$ of $\mathrm{MNZ}$ solution and two different concentrations of giniite particles $(0.2$ and $0.07 \mathrm{~g} / \mathrm{L}) .2 \mathrm{~mL}$ of $\mathrm{H}_{2} \mathrm{O}_{2}$ were added to the solution simultaneously with $\mathrm{pH}$ adjustment $(\mathrm{pH}=2.8)$ using $\mathrm{H}_{2} \mathrm{SO}_{4}$ or $\mathrm{NaOH}$. The experiments were then carried out under magnetic stirring for 9 hours and under sunlight radiation. The solar flux was measured every hour using a pyranometer (KIPP \& ZONEN, CMP11) coupled to a data acquisition software. The aliquots were withdrawn at regular times, subjected to vigorous centrifugation $(6000 \mathrm{rpm}, 20 \mathrm{~min})$ to remove the ginniite particles, and filtered through $0.45 \mathrm{~mm}$ Millipore filters. 


\subsection{Analytical methods}

The absorbance of MNZ was measured at defined intervals of time by UV-visible spectrophotometry (Shimadzu UV1800), in the range of 200-400 nm, and the photocatalytic degradation was analysed by the evaluating of the absorbance variation of the principal peak at $320 \mathrm{~nm}$, using $1 \mathrm{~cm}$ quartz cell. The photocatalytic efficiency (\%) was calculated using equation 1:

$$
R(\%)=\frac{\left(C_{0}-C\right)}{C_{0}} \times 100
$$

where $C_{0}$ and $C$ are the initial and equilibrium MNZ concentrations $(\mathrm{mg} / \mathrm{L})$, respectively.

MNZ mineralisation was evaluated by High-Performance Liquid Chromatography (HPLC, Waters, U.S.A.) equipped with a UV detector. The analytical column was a Diamonsil (R) C18 $(250 \times 4.6 \mathrm{~mm}, 5 \mu \mathrm{m})$, and the mobile phase was composed by acetonitrile/water, (30/70, v/v). The flow rate was set at $1.0 \mathrm{~mL} / \mathrm{min}$, and the injection volume was $20 \mu \mathrm{L}$. The detection wavelength was $348 \mathrm{~nm}$.

\section{RESULTS AND DISCUSSION}

\subsection{Giniite main characteristics}

The morphology of the obtained samples, synthesised by the different precursors $(\mathrm{LiOH}$, $\mathrm{NaOH}$ and K.O.H.) and the same $\mathrm{pH}=4$, is presented in the SEM images of Figure 2Figure 2. The obtained iron phosphates present different morphologies for each alkaline cations $\left(\mathrm{Li}^{+}, \mathrm{Na}^{+}\right.$ and $\mathrm{K}^{+}$) of the hydroxides precursors. Morphologies include asterisk-like (Figure 2Figure 2 (a)), flower-like (Figure 2Figure 2 (b)) and branches-like (Figure 2Figure 2 (c)), related to the use of LiOH (Li@giniite), $\mathrm{NaOH}$ ( $\mathrm{Na@giniite)} \mathrm{and} \mathrm{KOH}$ (K@ giniite) precursors, respectively. The Li@giniite sample is formed by four or five orthogonally arranged segments that hold a particle diameter between 5-10 $\mu \mathrm{m}$. The Na@giniite sample possesses pyramid-like intergrowths with uniform particle size between 5-6 $\mu \mathrm{m}$. The K@giniite sample form dendrites orthogonally arranged with sizes between $20-40 \mu \mathrm{m}$. 


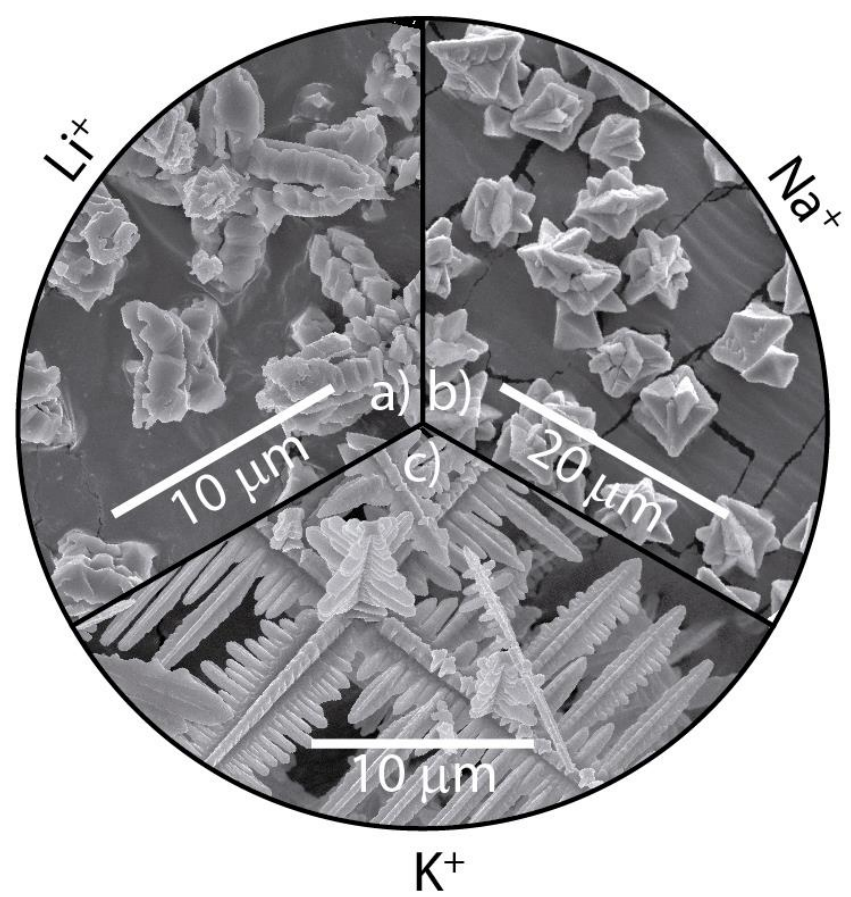

Figure 2. SEM images of the synthesised samples obtained with the (a) $\mathrm{LiOH}$, (b) $\mathrm{NaOH}$ and (c) $\mathrm{KOH}$ precursors.

The observed morphology variations among the different particles demonstrate that the cation precursors used in the hydrothermal synthesis, directly influence the morphology during the crystal grow. The interaction between each cation leads to cap the particle surface during the growth of the atomic planes. Comparing the lithium $\left(\mathrm{Li}^{+}\right)$and sodium $\left(\mathrm{Na}^{+}\right)$with the potassium $\left(\mathrm{K}^{+}\right)$cation, the last one favours a planar structure with high dimensions due to its higher atomic radius. In contrast, the smaller atomic radius cations $\left(\mathrm{Li}^{+}\right.$and $\left.\mathrm{Na}^{+}\right)$tend to yield smaller particles with orthogonal shape [19].

The surface areas of each structure were estimated by mercury intrusion porosimetry. The $\mathrm{Na} @$ giniite shows the highest surface area, $10.7 \mathrm{~m}^{2} / \mathrm{g}$, and the $\mathrm{K} @$ giniite the lowest one, 2.9 $\mathrm{m}^{2} / \mathrm{g}$. A more significant difference is observed between the Na@giniite spherical morphology and the branches-like morphology of K@ giniite.

The crystalline structure of each sample was studied by XRD using Le Bail fits, and the results are presented in Figure 3 Figure 3 (a), (b), and (c), showing that the samples crystallise as giniite structure, regardless of the cation used as a precursor, proven by the identification of characteristics peaks of giniite (JCPDS card no.: 45-1436). Moreover, all samples show welldefined peaks establishing the crystalline structure, and no other phases were found. The obtained diffractograms allowed to build a crystal structure, represented in Figure 3 (d). The presence of the studied alkaline cation during the synthesis does not influence the formation of 
the giniite crystalline structure. Since in this study, parameters as temperature, time and $\mathrm{pH}$ were well controlled and kept constant, it is possible to affirm that the addition of the different cations does not influence the giniite structure, but allows to control its morphology, as previously mentioned (Figure 2Figure 2) [24].
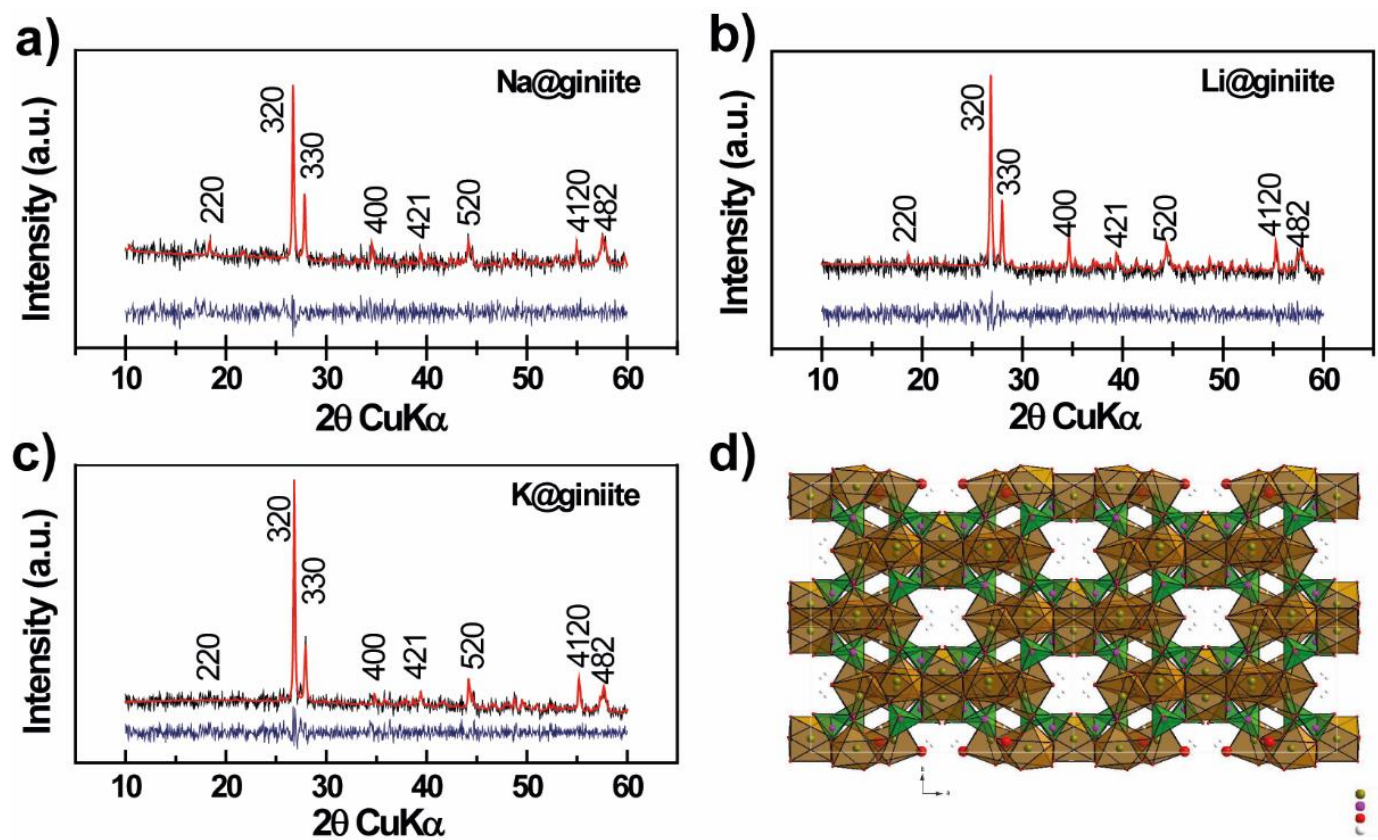

d)
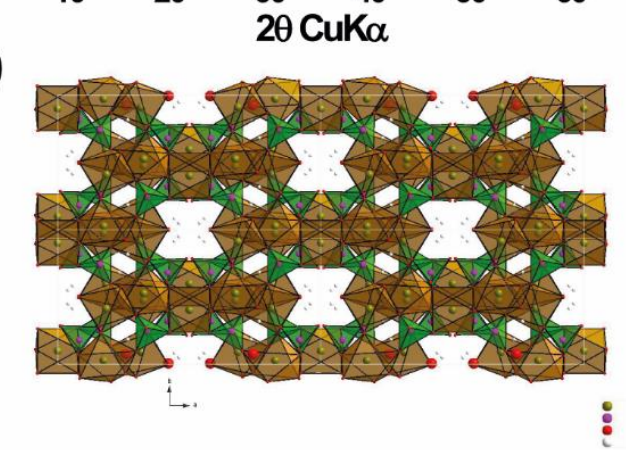

Figure 3. (a), (b), (c), Le Bail fits of the samples prepared by hydrothermal synthesis of giniite with different alkaline cations (giniite - JCPDS card no.: 45-1436), (d) giniite structure obtained using Crystal Maker ${ }^{\circledR}$ software and representing Fe (yellow), $\mathrm{P}$ (pink), $\mathrm{O}$ (red), and $\mathrm{H}$ (white).

FTIR also identified the giniite structure and the results (available in supplementary information, Figure S1) allows to identify the pure phase by the characteristics well- and broaddefined vibrational bands of giniite at 751, 775, 943, 998, 1021, and $1074 \mathrm{~cm}^{-1}$. The vibrational bands between 800 and $1074 \mathrm{~cm}^{-1}$ are assigned to the $\mathrm{PO}^{4}$ bonds (asymmetric stretching between the $\mathrm{P}$ and $\mathrm{O}$ atoms). For lower wavenumber, the bands at 751 and $775 \mathrm{~cm}^{-1}$ are assigned to the $\mathrm{Fe}$ and $\mathrm{O}$ bonds [24]. The absence of symmetric stretching phosphate groups at $923 \mathrm{~cm}^{-}$ ${ }^{1}$ also indicate the presence of the giniite phase without impurities.

\subsection{Fenton photocatalytic degradation of MNZ}

The Fenton photocatalytic activity of giniite particles was evaluated by exposure of MNZ $(10 \mathrm{mg} / \mathrm{L})$ to sunlight radiation, arround $853.15 \mathrm{~W} / \mathrm{m}^{2}$, for 9 hours. The results are presented in Figure 4Figure 4. 

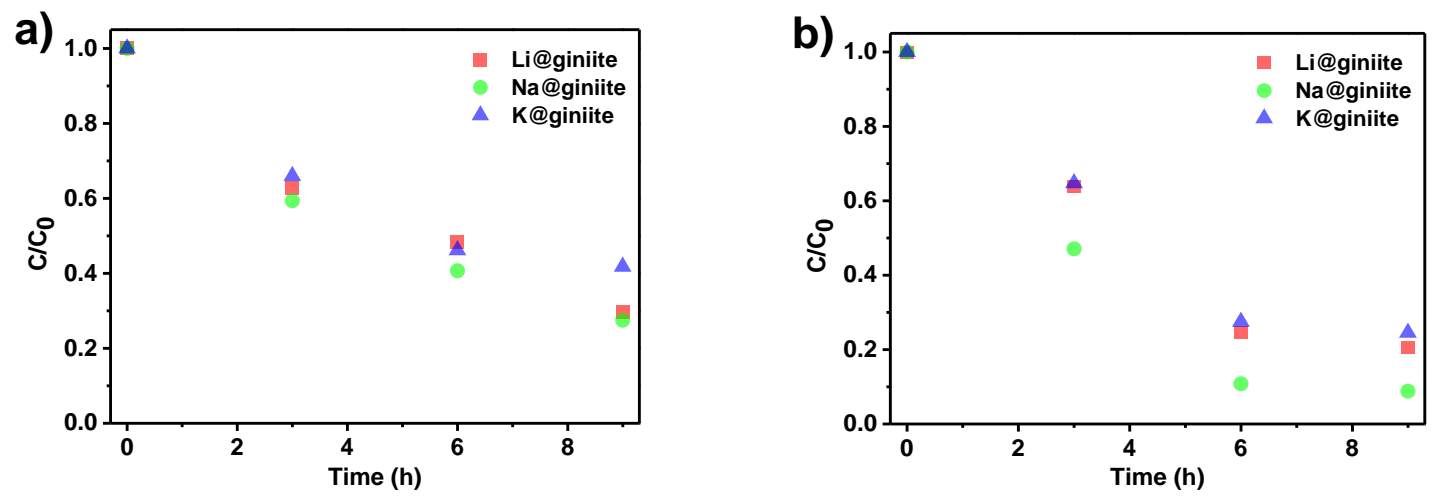

Figure 4. Photo-Fenton photocatalytic degradation of $\mathrm{MNZ}(10 \mathrm{mg} / \mathrm{L})$ at $\mathrm{pH}=2.8$ with (a) $0.07 \mathrm{~g} / \mathrm{L}$ and (b) $0.2 \mathrm{~g} / \mathrm{L}$ of giniite particles, under sunlight radiation exposure of 9 hours.

As a control test, the adsorption of MNZ to the surface of giniite particles was assessed in the dark. Additionally, a second control was performed by exposing MNZ to sunlight radiation without giniite particles. The MNZ removal was approximately $1 \%$, for both tests, after $9 \mathrm{~h}$ of the experiment (available in the supplementary information, Figure S2).

The degradation rates of MNZ were determined by fitting the pseudo-first-order model. Thereby, enough amount of $\mathrm{H}_{2} \mathrm{O}_{2}$ was produced in the Fenton process, and $\mathrm{OH}$ concentration was considered as constant. The apparent rate constants were determined by equation 2 :

$$
\ln \left(\frac{C_{0}}{C}\right)=k_{a p p} t
$$

where $C_{0}$ and $C$ are the initial and MNZ concentration at time $t$, respectively, and $k_{a p p}$ is the first-order rate constant.

Two different concentrations of giinite particles, 0.07 and $0.2 \mathrm{~g} / \mathrm{L}$, were tested to evaluate its effect on the degradation efficiency. Figure 4Figure 4 (a), indicates that $\mathrm{Na@giniite}(72.5 \%$ and $\left.0.1418 \mathrm{~h}^{-1}\right)$ and Li@giniite $\left(70.3 \%\right.$ and $\left.0.1301 \mathrm{~h}^{-1}\right)$ particles present the higher degradation efficiencies, while K@giniite present lower degradation efficiency and rate (58.2\% and 0.0992 $\left.\mathrm{h}^{-1}\right)$. Such differences are explained because of the significant morphology variations among the tested particles, as previously discussed and supported by Figure 2.

Figure 4Figure 4 (b) shows the degradation of MNZ with $0.2 \mathrm{~g} / \mathrm{L}$ of giniite. After $9 \mathrm{~h}$ of exposure to sun radiation, all the giniite samples show a degradation efficiency higher than 75\%. The highest degradation efficiency was observed with Na@giniite particles $(91.2 \%)$, while samples of Li@giniite and K@giniite presented similar degradation efficiencies (79.4\% 
and $75.5 \%$, respectively). The reaction rates indicated that $\mathrm{Na@giniite} \mathrm{particles} \mathrm{promoted} \mathrm{a}$ faster degradation of MNZ, with a reaction rate of $0.2918 \mathrm{~h}^{-1}$. Li@giniite and $\mathrm{K} @$ giniite presented similar reaction rates ( 0.1899 and $0.1692 \mathrm{~h}^{-1}$, respectively).

By analysis of both Figure 4Figure 4 (a) and (b) it is observed that higher concentrations of giniite result in enhanced efficiencies and degradation rates for all the tested giniites. The selected concentrations are within a range mentioned in literature, and the $0.2 \mathrm{~g} / \mathrm{L}$ concentrations seems to be enogh to attaim a complete MNZ degradations. However, only the $\mathrm{Na} @$ giniite represents a significant improvement of efficincy. The superior degradation efficiency and rate of $\mathrm{Na@giniite} \mathrm{particles} \mathrm{can} \mathrm{be} \mathrm{related} \mathrm{to} \mathrm{its} \mathrm{crystal} \mathrm{morphology} \mathrm{(Figure}$ 2Figure 2). Different alkaline cations lead to variations on the average size of particles and morphologies, which leads to changes in the surface area, causing the observed differences in degradation efficiencies. According to the surface area results, obtained through M.I.P., $\mathrm{Na} @$ giniite and $\mathrm{K} @$ giniite show a surface area of 10.7 and $2.9 \mathrm{~m}^{2} / \mathrm{g}$, respectively. In this way, $\mathrm{Na} @$ giniite offers a higher surface area and further active sites that allow MNZ adsorption to its surface, resulting in a superior degradation efficiency of $91.2 \%$.

Very few works were found related to giniite application to Fenton photocatalytic processes and listed in Table 1. Although this information allows putting in perspective our results, it is essential to highlight that direct comparison with our data are impossible, as the experimental conditions and methodology used in each work are different.

Table 1 - Comparative study on giniite application to Fenton photocatalytic degradation of contaminants.

\begin{tabular}{cccccccc}
\hline Pollutant & $\begin{array}{c}\text { Pollutant } \\
\text { concentration }\end{array}$ & Giniite & Size $(\boldsymbol{\mu m})$ & Radiation & $\begin{array}{c}\text { Degradation } \\
(\%)\end{array}$ & $\begin{array}{c}\text { Time } \\
(\mathbf{h})\end{array}$ & Ref. \\
\hline Rh B & $10 \mathrm{mg} / \mathrm{L}$ & $\begin{array}{c}20 \mathrm{mg} \\
(100 \mathrm{ml})\end{array}$ & $10-50$ & - & $\approx 99 \%$ & 1 & {$[25]$} \\
& & & & & & & \\
MB & $1 \times 10^{-5} \mathrm{M}$ & $\begin{array}{c}50 \mathrm{mg} \\
(100 \mathrm{ml})\end{array}$ & 20 & $\begin{array}{c}500 \mathrm{~W}(\lambda> \\
290 \mathrm{~nm})\end{array}$ & $\approx 100$ & 6 & {$[23]$} \\
$\mathrm{Rh} \mathrm{B}$ & $1 \times 10^{-5} \mathrm{M}$ & $\begin{array}{c}50 \mathrm{mg} \\
(100 \mathrm{ml})\end{array}$ & $3.5-4.5$ & $\begin{array}{c}300 \mathrm{~W}(\lambda \\
>420 \mathrm{~nm})\end{array}$ & $\approx 100$ & 2.5 & {$[26]$} \\
MB & $10 \mathrm{mg} / \mathrm{L}$ & $\begin{array}{c}30 \mathrm{mg} \\
(100 \mathrm{ml})\end{array}$ & $1.2-1.4$ & $\begin{array}{c}150 \mathrm{~W}(\lambda> \\
420 \mathrm{~nm})\end{array}$ & 99.5 & 2 & {$[12]$} \\
\hline
\end{tabular}

From the works listed in Table 1, it is possible to perceive that giniite proved is efficiency by completely degrading $\mathrm{RhB}$ and $\mathrm{MB}$ under different radiation intensities (from $150 \mathrm{~W}$ to 500 W) and exposure times, despite the different sizes used in the works (ranging from 20 to 1.2 $\mu \mathrm{m})$. However, these works use artificial radiation, making the process expensive; additionally, 
the presented works are focused on dyes degradation, which absorb visible range radiation and favours photodegradation. Our work tested higher volumes $(150 \mathrm{ml})$, used inexpensive sunlight radiation and focused on a recalcitrant micropollutant degradation, MNZ.

\subsection{Mineralisation and degradation mechanism of $\mathrm{MNZ}$}

UV-VIS and HPLC-UV analysis allowd to evaluate degradation the mineralisation of MNZ after the tretments with the different giniites, as presented in Figure 5 Figure 5.
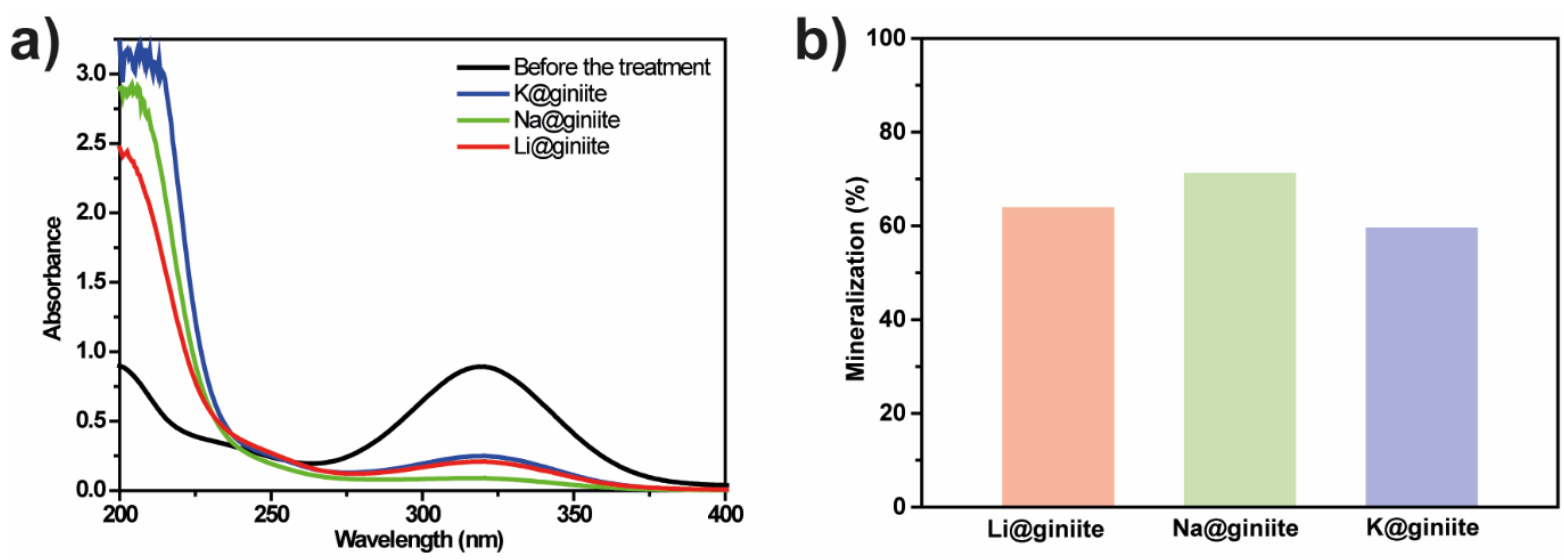

Figure 5. (a) UV-VIS spectra of MNZ. before and after the treatment with Li, Na, and K@ giniite; (b) Mineralisation of MNZ. by Li, Na, and K@giniite particles measured trough HPLC-UV.

The evaluation of mineralisation is a significant parameter, as unstable intermediates more toxic than MNZ can be produced in the photocatalytic process and remain in the solution due to incomplete mineralisation [27]. In fact, Figure 5Figure 5 shows that all the tested giniite particels are unable to completely mineralise MNZ. These particles achieve MNZ mineralisations around $60-72 \%$, and a mineralisation maximum of $71.5 \%$ is obtained for $\mathrm{Na} @$ giniite. Despite the significantly high mineralisation achieved, by-products may be present in water after the photocatalytic process. In this way, it is important to understand the MNZ degradation mechanism. A possible mechanism of MNZ degradation is illustrated in Figure 


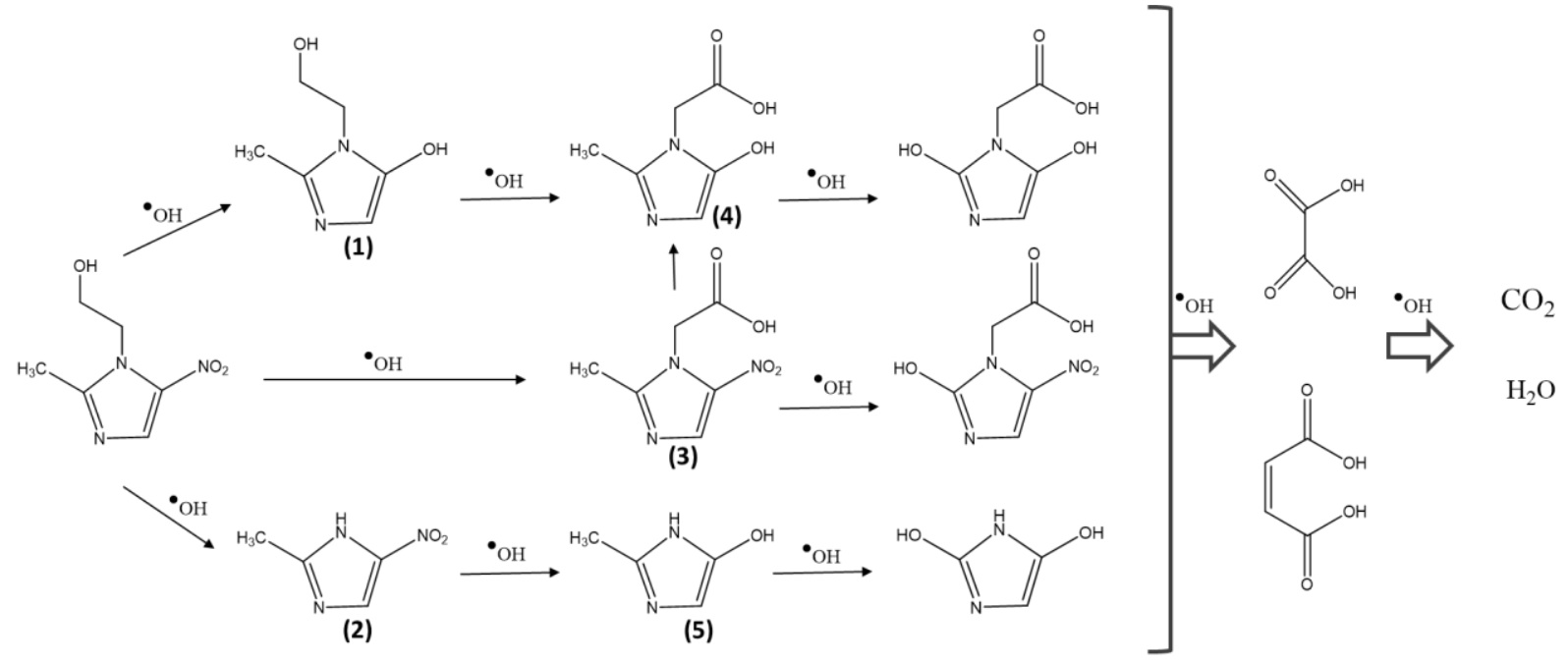

Figure 6. General degradation mechanism of MNZ (adapted from [28]).

One route for MNZ degradation is started by hydroxylation and denitration, leading to the formation of (1). This subproduct is then oxidised, and the subproduct (4) is formed. The second route initiates with the hydroxyethyl-cleavage of MNZ, producing (2). Similar reactions yield the formation of subproduct (5). The third route of $\mathrm{MNZ}$ is the ${ }^{\circ} \mathrm{OH}$ attack over the hydroxyethyl group, leading to the creation of (3), which is then oxidised to produce (4). Further oxidations of heterocyclic intermediates - subproducts (3), (4) and (5) - lead to the formation of carboxylic acids and the complete mineralisation into $\mathrm{CO}_{2}$ and $\mathrm{H}_{2} \mathrm{O}[28,29]$. According to the literature, the mineralisation of MNZ reduces its ecotoxic effects in aqueous solutions[30].

\section{CONCLUSIONS}

This work shows the influence of three different alkaline hydroxides $(\mathrm{NaOH}, \mathrm{LiOH}$, and $\mathrm{KOH})$ during the hydrothermal synthesis, in the crystal morphology of giniite and its Fenton photocatalytic activity against MNZ. The different types of alkaline cations promote different morphologies including asterisk-like, flower-like and branches-like for $\mathrm{LiOH}, \mathrm{NaOH}$ and $\mathrm{KOH}$, respectively, also resulting in different surface areas between 10.7 and $2.9 \mathrm{~m}^{2} / \mathrm{g}$ for $\mathrm{Na} @$ giniite and $\mathrm{K} @$ giniite, respectively. On the other hand, the pure crystalline structure and chemical structure of the giniite remain the same for the samples prepared with the different alkaline cations. Concerning the influence of catalyst concentration and alkaline cation in its efficiency, it is shown that giniite concentration plays an essential role in Fenton photocatalytic activity, increasing giniite concentration leading to more efficient degradation of MNZ. The alkaline cation has a significant impact on the photocatalytic activity, $\mathrm{Na} @$ giniite presenting the highest degradation efficiency when compared with Li and K@giniite (12 and 16\% higher efficiency 
for $0.2 \mathrm{~g} / \mathrm{L} ; 2$ and $14 \%$ higher efficiency for $0.07 \mathrm{~g} / \mathrm{L}$, respectively) mainly due to its higher surface area. Thus, the results indicate the suitability of $\mathrm{Na} @$ giniite particles for metronidazole and related compounds removal from water under sunlight radiation.

\section{Acknowledgements}

This work was supported by the Portuguese Foundation for Science and Technology (FCT) in the framework of the Strategic Funding UID/FIS/04650/2020 and PESTC/QUI/UIO686/2014 and under projects PTDC/BTM-MAT/28237/2017 and PTDC/FISMAC/28157/2017. We also thank the financial support from e FCT for grants SFRH/BD/122373/2016 (HS), SFRH/BPD/112547/2015 (CMC), IF/01516/2013 (SF), CTTI70/19-CF(1) (P.M), and CEECIND/00833/2017 (RG). The authors thank funding by the Spanish State Research Agency (AEI) and the European Regional Development Fund (ERFD) through the project PID2019-106099RB-C43 / AEI / 10.13039/501100011033 and from the Basque Government Industry and Education Department under the ELKARTEK, HAZITEK and PIBA (PIBA-2018-06) programs, respectively.

\section{References}

1. Liu, J., et al., F/W co-doped TiO2-SiO2 composite aerogels with improved visible light-driven photocatalytic activity. Journal of Solid State Chemistry, 2019. 275: p. 8-15.

2. Gao, Y., et al., Adsorption and removal of tetracycline antibiotics from aqueous solution by graphene oxide. Journal of Colloid and Interface Science, 2012. 368(1): p. 540-546.

3. Pérez, T., et al., Solar photoelectro-Fenton degradation of the antibiotic metronidazole using a flow plant with a Pt/air-diffusion cell and a CPC photoreactor. Electrochimica Acta, 2015. 165: p. 173-181.

4. Fang, Z., et al., Effective removal of antibiotic metronidazole from water by nanoscale zerovalent iron particles. Desalination, 2011. 268(1): p. 60-67.

5. Kümmerer, K., Drugs in the environment: emission of drugs, diagnostic aids and disinfectants into wastewater by hospitals in relation to other sources - a review. Chemosphere, 2001. 45(6): p. 957-969.

6. Gómez, M.J., et al., Determination of pharmaceuticals of various therapeutic classes by solidphase extraction and liquid chromatography-tandem mass spectrometry analysis in hospital effluent wastewaters. Journal of Chromatography A, 2006. 1114(2): p. 224-233.

7. Bendesky, A., D. Menéndez, and P. Ostrosky-Wegman, Is metronidazole carcinogenic? Mutation Research/Reviews in Mutation Research, 2002. 511(2): p. 133-144.

8. Gar Alalm, M., et al., Improved WO3 photocatalytic efficiency using ZrO2 and Ru for the degradation of carbofuran and ampicillin. Journal of Hazardous Materials, 2016. 302: p. 225231.

9. Gar Alalm, M., A. Tawfik, and S. Ookawara, Comparison of solar TiO2 photocatalysis and solar photo-Fenton for treatment of pesticides industry wastewater: Operational conditions, kinetics, and costs. Journal of Water Process Engineering, 2015. 8: p. 55-63. 
10. Gar Alalm, M., A. Tawfik, and S. Ookawara, Solar photocatalytic degradation of phenol by TiO2/AC prepared by temperature impregnation method. Desalination and Water Treatment, 2016. 57(2): p. 835-844.

11. Wang, N., et al., A review on Fenton-like processes for organic wastewater treatment. Journal of Environmental Chemical Engineering, 2016. 4(1): p. 762-787.

12. Zhang, X., et al., Facile preparation of ferric giniite hollow microspheres and their enhanced Fenton-like catalytic performance under visible-light irradiation. Journal of Colloid and Interface Science, 2015. 452: p. 24-32.

13. Park, H.-S., et al., Activated carbons impregnated with iron oxide nanoparticles for enhanced removal of bisphenol $A$ and natural organic matter. Journal of hazardous materials, 2015.

286: p. 315-324.

14. Huling, S.G., P.K. Jones, and T.R. Lee, Iron optimisation for Fenton-driven oxidation of MTBEspent granular activated carbon. Environmental Science and Technology, 2007. 41(11): p. 4090-4096.

15. Rouzies, D., et al., Isobutyric acid oxidative dehydrogenation over iron hydroxyphosphates. I. Catalytic properties and role of water. Applied Catalysis A, General, 1995. 124(2): p. 189-203.

16. Duan, $\mathrm{X}$., et al., Crystal-facet engineering of ferric giniite by using ionic-liquid precursors and their enhanced photocatalytic performances under visible-light irradiation. Chemistry - A European Journal, 2013. 19(22): p. 7231-7242.

17. Han, C., et al., Controllable synthesis of sphere- and star-like Fe $<$ inf $>5</$ inf $>$ $(P O<$ inf $>4</$ inf $>)<$ inf $>4</$ inf $>(O H)<$ inf $>3</$ inf $>\cdot 2 H<$ inf $>2</$ inf $>O$ microcrystals for effective photo-fenton-like degradation of rhodamine B. Inorganic and Nano-Metal Chemistry, 2017. 47(6): p. 806-809.

18. Li, D., et al., Controllable synthesis of Fe $<$ inf $>5</$ inf $>(P O<$ inf $>4</$ inf $>)$ $<\inf >4</$ inf $>(O H)<\inf >3</$ inf $>\cdot 2 \mathrm{H}<\inf >2</$ inf $>O$ as a highly efficient heterogeneous Fenton-like catalyst. CrystEngComm, 2011. 13(22): p. 6688-6693.

19. Gonçalves, R., et al., Crystal Morphology Control of Synthetic Giniite by Alkaline Cations and pH Variations. Crystal Growth and Design, 2017. 17(9): p. 4710-4714.

20. Laurent, S., et al., Magnetic iron oxide nanoparticles: Synthesis, stabilisation, vectorisation, physicochemical characterisations and biological applications. Chemical Reviews, 2008. 108(6): p. 2064-2110.

21. Iravani, S., et al., Synthesis of silver nanoparticles: Chemical, physical and biological methods. Research in Pharmaceutical Sciences, 2014. 9(6): p. 385-406.

22. Nejati, K. and R. Zabihi, Preparation and magnetic properties of nano size nickel ferrite particles using hydrothermal method. Chemistry Central Journal, 2012. 6(1).

23. Li, D., et al., Controllable synthesis of Fe5(PO4)4(OH)3.2H2O as a highly efficient heterogeneous Fenton-like catalyst. CrystEngComm, 2011. 13(22): p. 6688-6693.

24. Roncal-Herrero, T., et al., Precipitation of Iron and Aluminum Phosphates Directly from Aqueous Solution as a Function of Temperature from 50 to $200^{\circ} \mathrm{C}$. Crystal Growth \& Design, 2009. 9(12): p. 5197-5205.

25. Han, C., et al., Controllable synthesis of sphere- and star-like $\mathrm{Fe} 5(\mathrm{PO} 4) 4(\mathrm{OH}) 3 \bullet 2 \mathrm{H} 2 \mathrm{O}$ microcrystals for effective photo-Fenton-like degradation of rhodamine $B$. Inorganic and Nano-Metal Chemistry, 2017. 47(6): p. 806-809.

26. Duan, X., et al., Crystal-Facet Engineering of Ferric Giniite by Using lonic-Liquid Precursors and Their Enhanced Photocatalytic Performances under Visible-Light Irradiation. Chemistry (Weinheim an der Bergstrasse, Germany), 2013. 19.

27. Görmez, F., et al., Degradation of chloramphenicol and metronidazole by electro-Fenton process using graphene oxide-Fe3O4 as heterogeneous catalyst. Journal of Environmental Chemical Engineering, 2019. 7(2).

28. Nasiri, A., et al., New magnetic nanobiocomposite CoFe2O4@methycellulose: facile synthesis, characterisation, and photocatalytic degradation of metronidazole. Journal of Materials Science: Materials in Electronics, 2019. 
29. Yang, J., et al., Investigation of PAA/PVDF-NZVI hybrids for metronidazole removal: Synthesis, characterisation, and reactivity characteristics. Journal of Hazardous Materials, 2014. 264: p. 269-277.

30. Khataee, A.R., M. Fathinia, and S.W. Joo, Simultaneous monitoring of photocatalysis of three pharmaceuticals by immobilised TiO2 nanoparticles: Chemometric assessment, intermediates identification and ecotoxicological evaluation. Spectrochimica Acta Part A: Molecular and Biomolecular Spectroscopy, 2013. 112: p. 33-45. 